\title{
A New Mathematical Modeling of Banana Fruit and Comparison with Actual Values of Dimensional Properties
}

\author{
Mahmoud Soltani (Corresponding author) \\ Department of Agricultural Machinery Engineering, Faculty of Agricultural Engineering \& Technology \\ University of Tehran, P.O. Box 4111, Karaj 31587-77871, Iran \\ Tel: 98-919-165-7116_E-mail: mahmoodsoltani39@yahoo.com \\ Reza Alimardani \\ Department of Agricultural Machinery Engineering, Faculty of Agricultural Engineering \& Technology \\ University of Tehran, P.O. Box 4111, Karaj 31587-77871, Iran \\ Mahmoud Omid \\ Department of Agricultural Machinery Engineering, Faculty of Agricultural Engineering \& Technology \\ University of Tehran, P.O. Box 4111, Karaj 31587-77871, Iran \\ E-mail: omid@ut.ac.ir
}

\begin{abstract}
Banana (Cavendish variety) volume, projected area and surface area were estimated by mathematical approximation. The actual volume of banana was measured using water displacement method (WDM), also the actual projected area and surface area were measured by image processing (IP) technique. These parameters that calculated by mathematical methods were then compared to the actual values by the paired t-test and the Bland-Altman approach. The estimated volume and projected area were not significantly different from the volume determined using WDM $(\mathrm{P}>0.05)$ and projected area measured by IP technique $(\mathrm{P}>0.05)$, respectively. Although the estimated surface area was significantly different from the measured surface area by IP method, this mathematical estimation represented a good approximation of actual surface area. The mean difference between estimation method and WDM was $1.58 \mathrm{~cm}^{3}\left(95 \%\right.$ confidence interval: -0.011 and $\left.3.18 \mathrm{~cm}^{3} ; \mathrm{P}=0.058\right)$. There was a mean difference of $-0.71 \mathrm{~cm}^{2}\left(95 \%\right.$ confidence interval: -1.49 and $\left.0.074 \mathrm{~cm}^{2} ; \mathrm{P}=0.083\right)$ between mathematical estimation method and IP technique for projected area and $2.33 \mathrm{~cm}^{2}(95 \%$ confidence interval: 0.3 and $4.6 \mathrm{~cm}^{2} ; \mathrm{P}<0.05$ ) for surface area. WDM is time-consuming and absorbed water by banana during test may affect its physical properties. IP technique is very costly method but mathematical estimation does not require expensive apparatus.
\end{abstract}

Keywords: Banana fruit, Mathematical modeling, Volume, Surface area, Projected area

\section{Introduction}

Banana is one of the popular fruits in the world. Banana fruit is grown in many countries in sub-tropical and subsumed third place in the world fruits volume production after citrus fruit and grapes, thus it is necessary to investigate its variant properties. The volume and surface area of agricultural crops are utilized for many food science applications and studies (Wang \& Nguang, 2007). These parameters are important to indicate physical properties such as the water loss, gas permeability and weight per unit surface area, heat transfer, quantity of pesticide applications, respiration rates, evaluation of fruit growth and quality, respiration rate and ripeness index to forecast optimum harvest time (Eifert et al., 2006; Hahn \& Sanchez., 2000; Lee et al., 2006; Lorestani et al., 2006;Topuz et al., 2005; Wilhelm et al., 2005).The surface area and volume information is also used in food technology to predict the amounts of applied chemical, estimate peeling times, and determine the microbial concentrations present on the produce (Sabilov et al., 2002). Different mathematical models and numerical methods have been applied to estimate the surface area and volume. Wratten et al. (1969) assessed the surface area of rough rice by cutting it into sections using a microtome cutting machine. The surface area of each section was calculated by multiplying the thickness with the average perimeter of both elliptical peripheries and the total surface area of the rice was determined by summing the surface areas of all sections and the two circular areas 
representing both ends. Tabatabaeefar et al. (2000) modeled orange mass based on its dimensions. To estimate the volume of ellipsoidal food products theoretically, most of the researches approximated it by the volume equation of a perfect ellipsoid (Ahmed \& Sagar, 1981; Mohsenin, 1986), while others employed the modified equation with different constants (Somsen et al., 2004).

Image processing techniques have been employed in the fruit industry, especially for applications in quality inspection and shape sorting. Hahn \& Sanchez (2000) developed an imaging algorithm to measure the volume of non-circular shaped agricultural produce like carrots. Wang \& Nguang (2007) used image processing method to calculate the volume and surface area of axi-symmetric agricultural products. Koc (2007) determined the volume of watermelon by means of ellipsoid approximation and image processing and compared these methods with water displacement method to determine overall system accuracy. Khojastehnazhand et al. (2009) determined orange volume and surface area using image processing technique. In their study the image processing algorithm to determine the volume and surface area of orange was developed. The algorithm segmented the background and divides the image into a number of frustums of right elliptical cone. The volume and surface area of each frustum are computed by the segmentation method. The total volume and surface area of the orange is approximated as the sum of all elementary frustums.

The objective of this study was to develop a low cost and rapid estimation method for accurate calculation of volume, projected area and surface area of banana fruit based on mathematical simulation.

\section{Material and Methods}

Fifty fingers of full-ripe banana fruits were selected randomly from Damirchilo warehouse located in Karaj city of Tehran province and transferred to the Physical Properties of Materials Laboratory, Department of Agricultural Machinery Engineering, Faculty of Engineering and Technology, University of Tehran, Karaj, Iran. The banana fruits were divided into six planes of cut along the longitudinal axis of the fruit. At each plane of cut, the perpendicular diameters (Di, di) were measured to $0.01 \mathrm{~mm}$ accuracy by a digital caliper (Figure 1). The external and internal length of banana (Lo, Li) was measured by a flexible ruler (Figure 2).

The following expressions are developed for computing banana's volume (Equation 6), surface area (Equation 9) and projected area (Equation 12).

\subsection{Volume Estimation}

It was presumed that the cross section of banana is elliptical and the volume of each plane is performed by rotation of elliptical area about the center of curvature (Oi), as shown in Figure 3. The volume of each cushion is computed by the first Papus theorem (Equation 1).

$V i=\frac{\pi}{4} \theta i \operatorname{RiD}{ }^{\prime} i d^{\prime} i$

where $\theta i, \mathrm{Ri}, D^{\prime \prime} i$ and $d^{\prime \prime} i$ are obtained from the following relations:

$D^{\prime \prime} i=\frac{D i+D(i+1)}{2}$

$d^{\prime \prime} i=\frac{d i+d(i+1)}{2}$

$R i=\frac{L i}{2(L o-L i)} D^{\prime} i$

$\theta i=\frac{L i}{7 R i}$

The total volume of banana is obtained from summing the volume of each cushion as

$\mathrm{V}_{\text {total }}=\sum_{i=0}^{6} V i$ 


\subsection{Surface Area Estimation}

To calculate the surface area, the second Papus clause is used.

$S s i=\theta i R i P i$

where

$P i=\frac{\pi}{2}\left(D^{\prime}+d^{\prime} i\right)$

is the perimeter of elliptical section of each element. The total surface area is obtained by adding them up.

$\mathrm{Ss}_{\mathrm{total}}=\sum_{i=0}^{6} S s i$

\subsection{Projected Area Estimation}

The banana is divided in to seven sections and it is assumed each section is part of a ring. Mean value of ring thickness is obtained from Equation 2. Then the area of sectorial frustum is computed from Equation 10:

$S i=\frac{1}{2} \theta i\left[\left(R i+\frac{D^{\prime} i}{2}\right)^{2}-\left(R i+\frac{D^{\prime} i}{2}\right)^{2}\right]$

Equation 10 simplifies to:

$S i=\theta i R i D^{\prime} i$

The banana projected area is estimated by summing the area of individual element:

$\mathrm{S}_{\text {total }}=\sum_{i=0}^{6} S i$

The actual volume of bananas was measured using the water displacement method $\left(\mathrm{V}_{\mathrm{WDM}}\right)$. In this method the banana fruits were completely submerged in water and the mass of the displaced water was measured (Mohsenin, 1970). Even though this method is quite accurate, it is not ideal for objects that absorb water, thus to prevent this phenomena, experiment must be carried out rapidly.

The actual projected area and surface area were measured by image processing technique. This system consisted of the light emitting chamber (Sharifi et al., 2006) utilized as to emit light from behind the fruit. The equipment was set as a whole are composed of the three different basic sections of light source, diffuser, and camera holding stand. The function of the light source (4. 20W lamps) is to emit light to the bottom section of the diffuser. The diffuser task is to diffuse light at its level. The camera (model CANON POWERSHUT A85, Japan) was mounted about $40 \mathrm{~cm}$ above the diffuser. To measure the projected area, the banana was set on the plan on its lateral surface and the image was captured, then the banana was peeled, the rind was set between the diffuser and a vitreous brede to tabulate it and the image was acquired again.

The acquired images from digital camera were transferred to the MATLAB 7.0.4 software and the area was computed. System calibration was performed by attaching a quadrangular card $\left(100 \mathrm{~cm}^{2}\right.$ area $)$. The card was employed to provide pixel per $\mathrm{cm}^{2}$ ratio. A single grayscale threshold was used to determine if an image pixel belongs to the background or the object. Once the threshold was determined, the object boundary can be traced.

The paired t-test and the mean difference confidence interval approach were used to compare the volume, projected area and surface area of banana determined from mathematical approximation with the actual values of them that were calculated with water displacement method (volume) and image processing (projected area and surface area). The Bland - Altman (1999) approach was used to plot the agreement between measured parameters with the mathematical approximation. These analyses were performed using the Excel Analysis Toolpack option (MS Corporation, Redmond, WA, USA).

\section{Results and discussion}

The volume estimated by mathematical approximation was compared with the volume measured by water displacement when is shown in Table 1. A plot of the volumes determined by mathematical approximation and water displacement is shown in Figure 4. The regression coefficient was obtained 0.9741. It means that this method is sufficiently reliable to predict the volume of banana fruit. The mean values of volume difference 
between estimated volume and water displacement was $d 1=1.58 \mathrm{~cm}^{3}(95 \%$ confidence interval:- 0.011 and 3.18 $\mathrm{cm}^{3}$ ). The standard deviation of the volume differences was $\operatorname{Sd}_{1}=5.51 \mathrm{~cm}^{3}$. The paired samples $t$-test results showed that the banana volume measured with water displacement was not significantly different than the volume estimated with mathematical approximation $(\mathrm{P}=0.058)$, (Table 2$)$. The volume differences between two methods were normally distributed and $95 \%$ of the volume differences were expected to lie between $\mathrm{d}_{1}-1.96 \mathrm{Sd}_{1}$ and $\mathrm{d}_{1}+1.96 \mathrm{Sd}_{1}$, known as $95 \%$ limits of agreement (Bland \& Altman., 1999). The $95 \%$ limits of agreement for comparison of volumes measured with water displacement and mathematical estimation were calculated at -9.22 and $12.38 \mathrm{~cm}^{3}$ (Figure 5). Volumes estimated by mathematical approximation may be about $9.22 \mathrm{~cm}^{3}$ lower or $12.38 \mathrm{~cm}^{3}$ higher than volumes measured with water displacement method.

The values of the projected areas measured by image processing method $\left(\mathrm{S}_{\mathrm{IP}}\right)$ and the mathematical method $\left(\mathrm{S}_{\mathrm{E}}\right)$ are presented in Table 1. The results of comparison between estimated $\left(\mathrm{S}_{\mathrm{E}}\right)$ and measured $\left(\mathrm{S}_{\mathrm{IP}}\right)$ values with $\mathrm{R}^{2}$ $=0.9517$ are shown in Figure 6. The mean projected area difference between the two methods was $d 2=-0.71$ $\mathrm{cm}^{2}$ (95\% confidence interval: -1.49 and $\left.0.074 \mathrm{~cm}^{2}\right)$. The standard deviation of the projected area differences was $s d 2=2.7 \mathrm{~cm}^{2}$. The paired $t$-test results showed that the projected area estimated was not significantly different than the actual projected area measured by image processing method $(\mathrm{P}=0.083)$, (Table 2$)$. The projected area differences between image processing technique and estimated method were also normally distributed and the $95 \%$ limits of agreement in comparing these two methods were calculated to be -6 and $4.59 \mathrm{~cm}^{2}$ (Figure 7). Figure 7 shows that banana size has no effect on the accuracy of estimated projected area.

The estimated surface area $\left(\mathrm{Ss}_{\mathrm{E}}\right)$ and measured surface by image processing $\left(\mathrm{Ss}_{\mathrm{IP}}\right)$ are presented in Table 1 . The results of comparison between estimated $\left(\mathrm{Ss}_{\mathrm{E}}\right)$ and measured $\left(\mathrm{SS}_{\mathrm{IP}}\right)$ values with $\mathrm{R}^{2}=0.9512$ are shown in Fig 8 . The mean surface area difference between the two methods was $d 3=2.33 \mathrm{~cm}^{2}(95 \%$ confidence interval: 0.3 and $4.6 \mathrm{~cm}^{2}$ ). The standard deviation of the projected area differences was $s d 3=7.03 \mathrm{~cm}^{2}$. The paired $t$-test results showed that the surface area estimated was significantly different than the actual surface area measured by image processing method $(\mathrm{P}<0.05)$ (Table 2 ). The projected area differences between image processing technique and estimated method were also normally distributed and the $95 \%$ limits of agreement in comparing these two methods were calculated to be -11.46 and $16.12 \mathrm{~cm}^{2}$ (Figure 8). Figure 8 shows that banana size has no effect on the accuracy of estimated surface area.

\section{Conclusion}

Mathematical approximation was employed to estimate the volume, projected area and surface area of banana fruit. This method was compared with water displacement method for the volume and image processing technique for projected area and surface area. The difference between estimated volume $\left(\mathrm{V}_{\mathrm{E}}\right)$ and measured volume $\left(\mathrm{V}_{\mathrm{VDM}}\right)$ also estimated projected area $\left(\mathrm{S}_{\mathrm{E}}\right)$ and measured area $\left(\mathrm{S}_{\mathrm{IP}}\right)$ were not statistically significant $(\mathrm{P}>$ 0.05). Water displacement method is time-consuming technique, also absorbed water by banana is affected on its properties. Image processing technique is very costly method but mathematical estimation does not require to expensive apparatuses. The average of absolute percentage difference for estimated volume and measured volume was $2.98 \%$ also for estimated projected area and surface area with image processing technique were $3.36 \%$ and $2.88 \%$ respectively. The Bland-Altman approach indicated that the size of banana has no effect on the estimation of these parameters.

\section{Acknowledgement}

The financial support provided by the Research Department of University of Tehran, Iran, is duly acknowledged.

\section{References}

Ahmed, C. M. S \& Sagar, G. R. (1981). Volume increase of individual tubers of potatoes grown under field conditions. Potato Res., 24, 279-288.

Bland, J. M., \& Altman, D. G. (1999). Measuring agreement in method comparison studies. Stat.Meth.Med.Res, 8, 135-160.

Eifert, J. D., Sanglay, G. C., Lee, D. J., Sumner, S. S., \& Pierson, M. D. (2006). Prediction of raw produce surface area from weight measurement. J. Food Eng, 74, 552-556.

Hahn, F., \& Sanchez, S. (2000). Carrot volume evaluation using imaging algorithms. J. Agric. Eng. Res, 75, 243-249.

Khojastehnazhand, M., Omid, M., \& Tabatabaeefar, A. (2009). Determination of orange volume and surface area using image processing technique. Int. Agrophysics, 23, 237-24. 
Koc, A. B. (2007). Determination of watermelon volume using ellipsoid approximation and image processing. Postharvest Biolo. Technol, 45(3), 366-371.

Lee, D. J., Xu, X., Eifert, J., \& Zhan, P. (2006). Area and volume measurements of objects with irregular shapes using multiple silhouettes. Optical Eng., 45(2), 1-10.

Lorestani, A. N., Omid, M., Bagheri-Shooraki, S., Borghei, A. M., \& Tabatabaeefar, A. (2006). Design and evaluation of a fuzzy logic based decision support system for grading of Golden Delicious apples. Int. J. Agric. Biolo, 8(4), 440-444.

Lorestani, A. N., \& Tabatabaeefar, A. (2006). Modeling the mass of kiwi fruit by geometrical attributes. Int. Agrophysics, 20,135-139.

Mohsenin, N. N. (1970). Physical Properties of Plant and Animal Materials. Gordon and Breach Press, New York, NY, USA

Mohsenin, N. N. (1986). Physical properties of plant and animal materials. New York, USA: Gordon and Breach Publishers.

Sabliov, C. M., Boldor, D., Keener K. M., \& Farkas, B.E. (2002). Image processing method to determine surface area and volume of axi-symmetric agricultural products. Int. J. Food Prop, 5, 641-653.

Tabatabaeefar, A., Vefagh - Nematolahee, A., \& Rajabipour, A. (2000). Modeling of orange mass based on dimensions. J. Agr. Sci. Tech, 2, 299-305.

Topuz, A., Topakci, M., Canakci, M., Akinci, I., \& Ozdemir, F. (2005). Physical and nutritional properties of four orangevarieties. J. Food Eng. Res, 66, 519-523.

Sharifi,M., Rafiee, S., Keyhani, A., Jafari, A., Mobli, H., Rajabipour, A., \& Akram, A. (2007). Some physical properties of orange (var. Tompson). Int. Agrophysics, 21, 391-397.

Somsen, D., Capelle, A., \& Tramper, J. (2004). Manufacturing of par fried French-fries: Part 1: Production yield as a function of number of tubers per kilogram. J. Food Eng., 61(2),191-198.

Wang, T.Y., \& Nguang, S. K. (2007). Low cost sensor for volume and surface area computation of axi-symmetric agricultural products. J. Food Eng., 79, 870-877.

Wilhelm, L. R., Suter, D. A., \& Brusewitz, G. H. (2005). Physical Properties of Food Materials. Food and Process Engineering Technology. ASAE Press, St. Joseph, MI, USA.

Wratten, F.T., Poole, W. D., Cheness, J. L., Bal, S., \& Ramarao, V. V. (1969). Physical and thermal properties of rough rice. ASAE Transaction, 12(6), 801-803. 
Table 1. Estimated volume, projected area and surface area and measured volume, projected area and surface area $\left(\mathrm{V}_{\mathrm{E}}, \mathrm{S}_{\mathrm{E}}, \mathrm{Ss}_{\mathrm{E}}\right.$ and $\left.\mathrm{V}_{\mathrm{M}}, \mathrm{S}_{\mathrm{M}}, \mathrm{Ss}_{\mathrm{M}}\right)$ of banana fruits.

\begin{tabular}{|c|c|c|c|c|c|c|c|c|c|c|c|c|c|}
\hline No & $\begin{array}{c}V_{E} \\
\left(\mathrm{~cm}^{3}\right)\end{array}$ & $\begin{array}{l}\mathrm{V}_{\mathrm{WDM}} \\
\left(\mathrm{cm}^{3}\right)\end{array}$ & $\begin{array}{c}\mathrm{S}_{\mathrm{E}} \\
\left(\mathrm{cm}^{2}\right)\end{array}$ & $\begin{array}{c}\mathrm{S}_{\mathrm{IP}} \\
\left(\mathrm{cm}^{2}\right)\end{array}$ & $\begin{array}{c}\mathrm{Ss}_{\mathrm{E}} \\
\left(\mathrm{cm}^{2}\right)\end{array}$ & $\begin{array}{c}\mathrm{Ss}_{\mathrm{IP}} \\
\left(\mathrm{cm}^{2}\right)\end{array}$ & No & $\begin{array}{c}V_{E} \\
\left(\mathrm{~cm}^{3}\right)\end{array}$ & $\begin{array}{l}\mathrm{V}_{\mathrm{WDM}} \\
\left(\mathrm{cm}^{3}\right)\end{array}$ & $\begin{array}{c}\mathrm{S}_{\mathrm{E}} \\
\left(\mathrm{cm}^{2}\right)\end{array}$ & $\begin{array}{c}\mathrm{S}_{\mathrm{IP}} \\
\left(\mathrm{cm}^{2}\right)\end{array}$ & $\begin{array}{c}\mathrm{Ss}_{\mathrm{E}} \\
\left(\mathrm{cm}^{2}\right)\end{array}$ & $\begin{array}{c}\mathrm{Ss}_{\mathrm{IP}} \\
\left(\mathrm{cm}^{2}\right)\end{array}$ \\
\hline 1 & 167.6 & 175.8 & 71.8 & 77.3 & 197.19 & 209.96 & 24 & 145.2 & 136.5 & 58.2 & 57.4 & 166.69 & 158.37 \\
\hline 2 & 189.2 & 185.9 & 76.5 & 73.3 & 213.07 & 206.01 & 25 & 107.8 & 113.0 & 50.3 & 53.8 & 141.13 & 148.85 \\
\hline 3 & 158.8 & 152.9 & 67.5 & 67.7 & 186.84 & 185.82 & 26 & 151.0 & 154.1 & 62.5 & 63.0 & 176.73 & 174.20 \\
\hline 4 & 197.8 & 196.0 & 76.0 & 74.7 & 216.53 & 207.67 & 27 & 116.0 & 122.4 & 54.0 & 57.0 & 150.37 & 157.31 \\
\hline 5 & 192.1 & 190.2 & 73.8 & 72.5 & 208.64 & 199.54 & 28 & 155.3 & 154.9 & 63.3 & 59.7 & 177.90 & 176.19 \\
\hline 6 & 158.2 & 156.7 & 69.4 & 68.8 & 190.36 & 189.20 & 29 & 141.5 & 141.8 & 63.4 & 63.8 & 169.35 & 169.03 \\
\hline 7 & 165.7 & 154.3 & 71.9 & 68.9 & 192.11 & 189.91 & 30 & 142.5 & 147.4 & 61.4 & 61.1 & 168.91 & 178.62 \\
\hline 8 & 193.2 & 181.4 & 70.8 & 72.3 & 211.16 & 199.14 & 31 & 151.4 & 146.7 & 61.1 & 65.3 & 173.01 & 165.50 \\
\hline 9 & 177.7 & 181.1 & 72.8 & 75.8 & 202.12 & 200.50 & 32 & 152.0 & 150.8 & 62.4 & 62.1 & 173.83 & 172.42 \\
\hline 10 & 223.7 & 214.4 & 83.7 & 82.5 & 234.71 & 219.25 & 33 & 155.2 & 153.8 & 59.8 & 63.0 & 172.70 & 173.61 \\
\hline 11 & 217.5 & 205.6 & 85.5 & 80.1 & 227.84 & 224.47 & 34 & 156.9 & 153.2 & 61.7 & 62.9 & 176.27 & 173.71 \\
\hline 12 & 230 & 236.8 & 102.9 & 99.2 & 271.35 & 252.77 & 35 & 163.2 & 164.9 & 60.6 & 63.7 & 179.23 & 176.06 \\
\hline 13 & 158.8 & 157.7 & 61.9 & 67.7 & 182.86 & 183.40 & 36 & 153.6 & 148.0 & 57.8 & 59.6 & 167.54 & 165.48 \\
\hline 14 & 258.4 & 254.2 & 93.4 & 91.5 & 262.29 & 246.88 & 37 & 147.4 & 142.5 & 66.1 & 63.7 & 174.88 & 175.56 \\
\hline 15 & 222.2 & 215.9 & 90.1 & 89.3 & 239.07 & 232.92 & 38 & 141.6 & 136.3 & 58.3 & 59.3 & 163.88 & 163.85 \\
\hline 16 & 247.1 & 249.6 & 92.4 & 91.5 & 245.00 & 235.99 & 39 & 150.8 & 148.3 & 63.3 & 61.8 & 174.18 & 169.61 \\
\hline 17 & 224.8 & 222.2 & 92.9 & 95.4 & 244.45 & 233.45 & 40 & 148.5 & 145.1 & 62.0 & 60.0 & 172.42 & 164.75 \\
\hline 18 & 157.3 & 168.8 & 65.6 & 69.9 & 181.19 & 194.17 & 41 & 150.9 & 150.9 & 59.5 & 61.9 & 170.47 & 171.12 \\
\hline 19 & 164.4 & 159.8 & 65.6 & 69.8 & 189.27 & 192.94 & 42 & 164.6 & 156.7 & 60.3 & 63.8 & 179.83 & 175.76 \\
\hline 20 & 167.5 & 179.1 & 70.0 & 74.1 & 193.75 & 203.84 & 43 & 163.1 & 159.1 & 62.9 & 63.2 & 181.63 & 175.86 \\
\hline 21 & 210.8 & 212.8 & 83.2 & 87.2 & 232.52 & 237.96 & 44 & 136.1 & 136.4 & 57.6 & 59.9 & 164.02 & 163.68 \\
\hline 22 & 222 & 221.9 & 86.2 & 87.1 & 240.14 & 245.24 & 45 & 145.4 & 145.5 & 61.6 & 61.4 & 171.91 & 168.72 \\
\hline 23 & 143.2 & 137.8 & 56.1 & 59.1 & 169.21 & 163.60 & 46 & 133.8 & 130.0 & 60.0 & 57.3 & 163.70 & 162.24 \\
\hline
\end{tabular}


Table 2. The t-test analyses on comparing volume, projected area and surface area measurement method

\begin{tabular}{|c|c|c|c|}
\hline Parameters & $\begin{array}{c}\text { Volumes } \\
\left(\mathrm{V}_{\text {WDM }} \text { and } \mathrm{V}_{\mathrm{E}}\right)\end{array}$ & $\begin{array}{c}\text { Projected areas } \\
\left(\mathrm{S}_{\mathrm{IP}} \text { and } \mathrm{S}_{\mathrm{E}}\right)\end{array}$ & $\begin{array}{c}\text { Surface areas } \\
\left(\mathrm{Ss}_{\mathrm{IP}} \text { and } \mathrm{Ss}_{\mathrm{E}}\right)\end{array}$ \\
\hline Paired t-test & Same $(\mathrm{P}=0.058)$ & Same $(\mathrm{P}=0.083)$ & Different $(\mathrm{P}<0.05)$ \\
\hline $\begin{array}{c}\text { 95\% confidence interval } \\
\text { for the mean difference }\end{array}$ & $-0.011 ; 3.18$ & $-1.49 ; 0.074$ & $0.3 ; 4.6$ \\
\hline
\end{tabular}

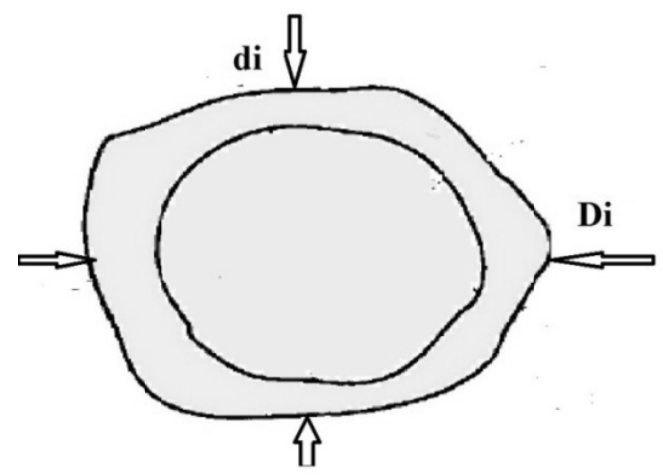

Figure 1. Plane of cut along the longitudinal axis of the banana

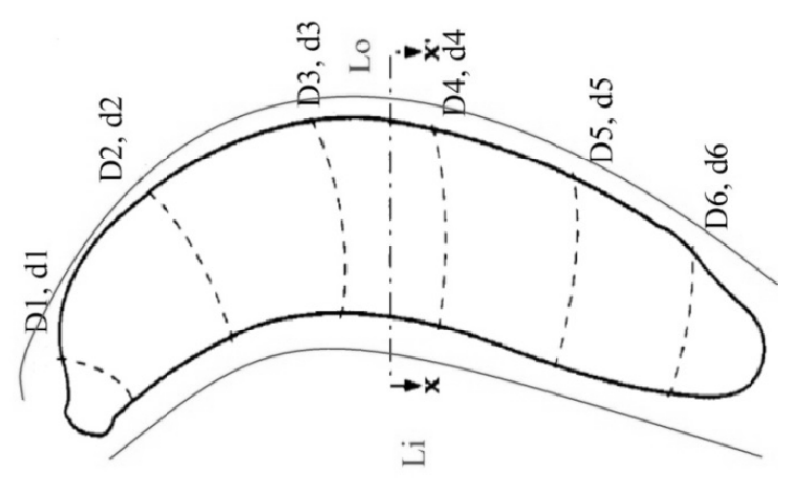

Figure 2. Longitudinal section of banana fruit with peel 


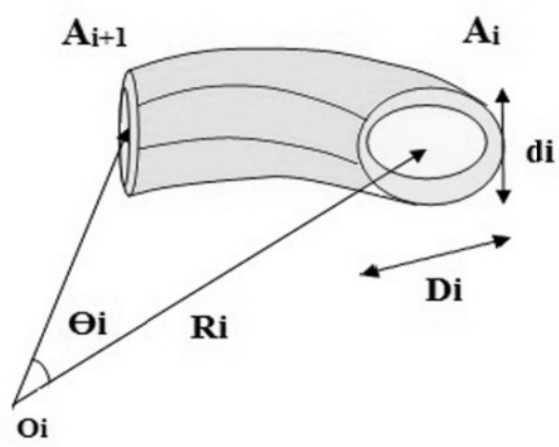

Figure 3. Clavicle shape of each banana section

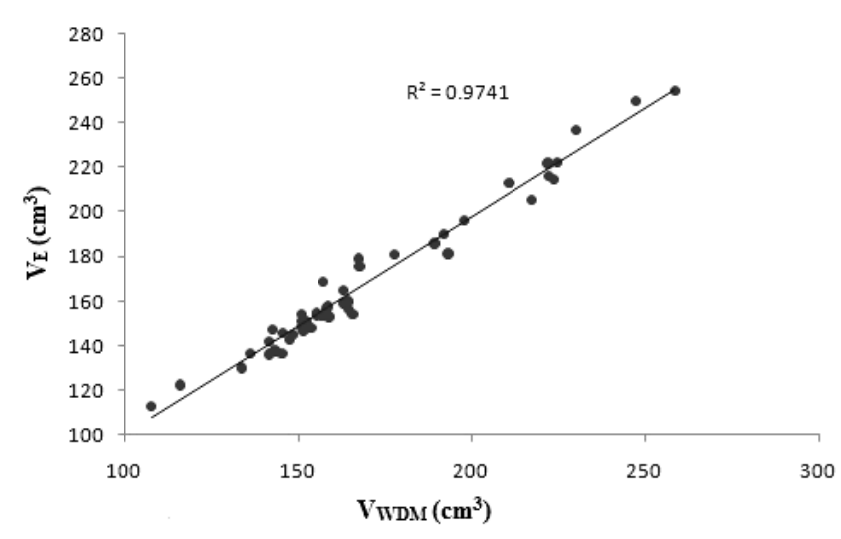

Figure 4. Banana volume measured using water displacement $\left(\mathrm{V}_{\mathrm{WDM}}\right)$ method and estimation method $\left(\mathrm{V}_{\mathrm{E}}\right)$ with the line of equality

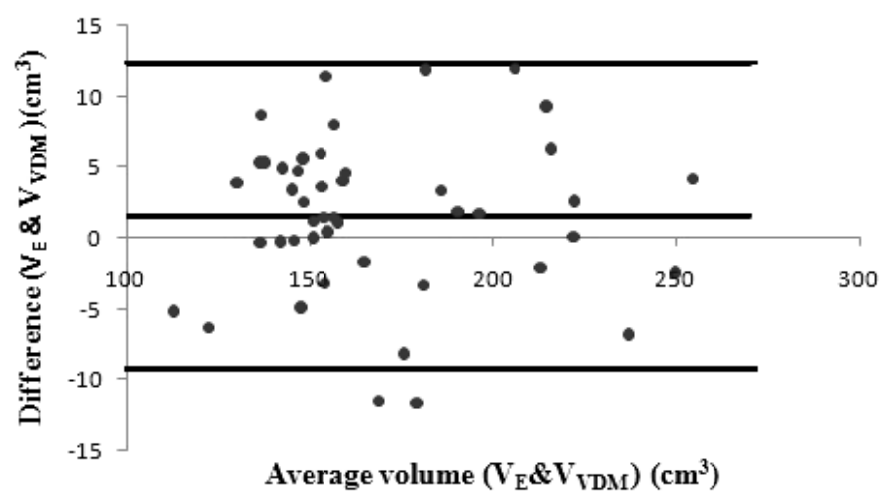

Figure 5. Bland-Altman plot for the comparison of banana volumes measured with water displacement and estimated volume by mathematical approximation; outer lines indicate the $95 \%$ limits of agreement $(-9.22 ; 12.38)$ and center line shows the average difference 


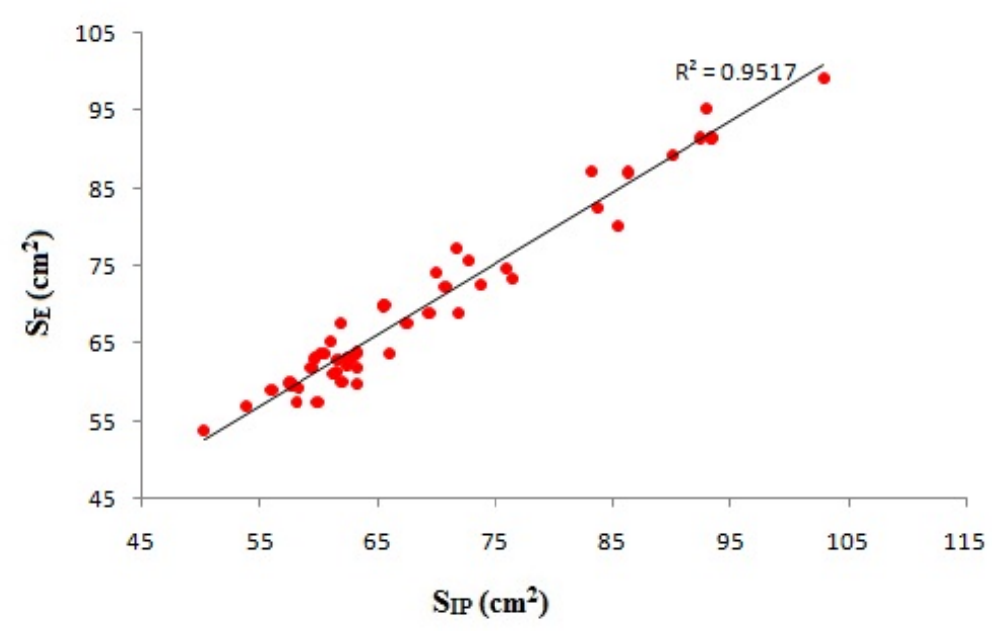

Figure 6. Banana projected area measured using image processing technique $\left(\mathrm{S}_{\mathrm{IP}}\right)$ and estimation method $\left(\mathrm{S}_{\mathrm{E}}\right)$ with the line of equality

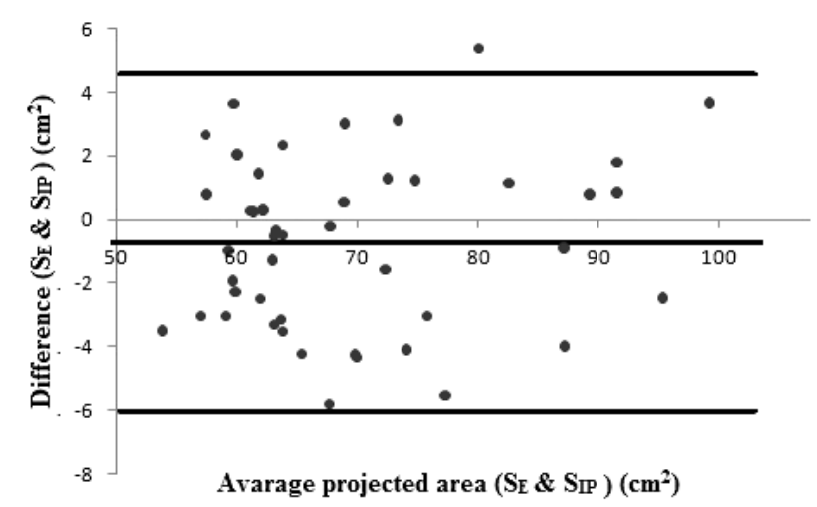

Figure 7. Bland-Altman plot for the comparison of banana projected area measured with image processing technique and estimated projected area by mathematical approximation; outer lines indicate the $95 \%$ limits of agreement $(-6 ; 4.59)$ and center line shows the average difference

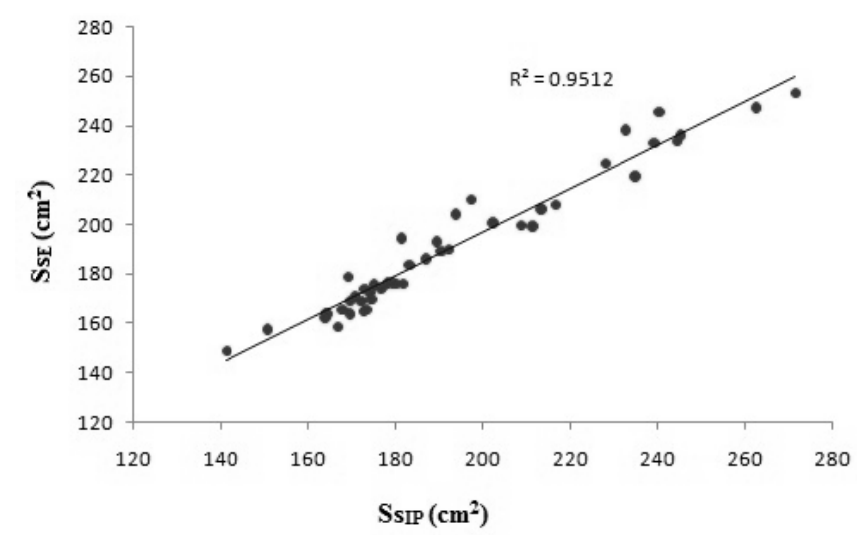

Figure 8. Banana surface area measured using image processing technique $\left(\mathrm{Ss}_{\mathrm{IP}}\right)$ and estimation method $\left(\mathrm{Ss}_{\mathrm{E}}\right)$ with the line of equality 


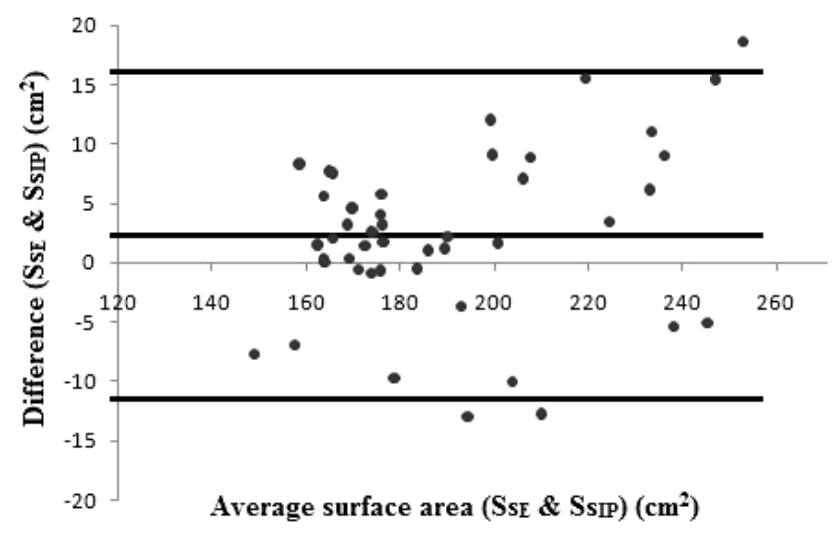

Figure 9. Bland-Altman plot for the comparison of banana surface area measured with image processing technique and estimated surface area by mathematical approximation; outer lines indicate the $95 \%$ limits of agreement $(-11.46 ; 16.12)$ and center line shows the average difference 